\title{
Micro-encapsulation of Eugenia supra-auxillaris phenolics Rich Fraction for Its Possible Use as a Natural Food Preservative
}

\author{
Hoda S. El-Sayed ${ }^{1}$, Heba H.Salama ${ }^{1}$, Kawther El-Shafei ${ }^{1}$ and Nesrine M. Hegazi ${ }^{2 *}$ \\ ${ }^{1}$ Department of Dairy Science, Division of Food Industries and Nutrition, National \\ Research Centre, Dokki, Cairo, Egypt and ${ }^{2}$ Department of Phytochemistry and Plant \\ Systematics, Division of Pharmaceutical Industries, National Research Centre, Cairo, \\ Egypt.
}

\begin{abstract}
$7^{U G E N I A}$ supra-auxillaris (family Myrtaceae) leaves were explored for their total

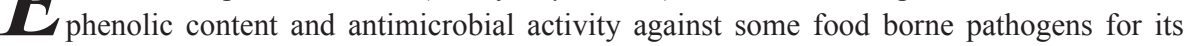
probable use as a food preservative. The total extract of $E$. supra-auxillaris exhibited significant antimicrobial activity against Bacillus cereus, Bacillus subtilis, Pseudomonas aeruginosa and Aspergillus niger at concentration of $100 \mathrm{mg} / \mathrm{ml}$. Upon fractionation, the ethyl acetate fraction appeared to be more potent than the $n$-butanol fraction in inhibiting bacterial and fungal growth and had higher polyphenolic content. Three phenolic compounds were isolated and identified from the bioactive fraction. The impact of microencapsulation of the ethyl acetate fraction with sodium alginate $(2 \%)$ was investigated. The micro-encapsulated fraction retained its antimicrobial activity at a concentration as low as $25 \mathrm{mg} / \mathrm{ml}$. Since the tested pathogens are frequent candidates causing food-borne illnesses, it would be interesting to investigate the potentiality of their possible application in food to increase shelf life or promote safety.
\end{abstract}

Keywords: Eugenia supra-auxillaris, Phenolics, micro-encapsulation, anti-microbial, Sodium alginate.

\section{Introduction}

Food borne illnesses are a main apprehension for consumers, food industry, and food safety authorities. Recently, significant effort has been made to study natural antimicrobials that can inhibit bacterial and fungal growth in food for the enhancement of its quality and shelf-life. By the same token, consumers have become more conscious about the safety of synthetic preservatives used in food. Thus, there is snowballing appeal for natural products that can serve as alternate food preservatives [1].

Research on the application of polyphenols have gained great attention in the food and nutraceutical industries, for their favorable effects on human health [2]. They are used in numerous sectors of the food-processing industry as natural additives (natural coloring agents, preservative agents, natural antioxidants, nutritional additives). However, the effective usage of polyphenols is influenced by retaining the stability, bioactivity and bioavailability of the active compounds.
Regrettably, they oxidize very quickly, leading to the progressive appearance of a brown color and/or undesirable odors with a considerable loss in activity. Their effective use as natural preservatives is restricted by their instability during food processing, distribution or storage. In addition to their astringent and bitter taste which restrains their application in food industry

The stability of polyphenols could be improved using microencapsulation technologies [3], to be used in industrial purposes and to ensure its bioavailability. Microencapsulation is a practice wherein a bioactive compound is incorporated within a biopolymer, in this manner protecting it from oxygen, water or other conditions in order to improve its stability [3].

Nowadays, various microencapsulation methods are available [4-7], and the microencapsulated products are widely used in the food, pharmaceutical and cosmetic industries.

An interesting potential encapsulation 
agent maybe sodium alginate which has proven to offer proficient protection when used as coating material, resulting in high encapsulation efficiency values for phenolic compounds extracted from plants [8-11]. Alginate is a natural anionic polyelectrolyte obtained from numerous species of brown algae (Phaeophyceae) and of bacteria (Azobacter vinelandii). It is composed of unbranched binary copolymers of $(1 \rightarrow 4)$ linked $\beta$-D-mannuronic acid (M) and $\alpha$-L-guluronic acid $(\mathrm{G})$ residues of widely varying composition and sequence [12]. This polymer features several qualities that make it a proper choice material for encapsulation, such as low cost, simplicity to use, biodegradability, biocompatibility, and capability to undergo chain-chain association and form three dimensional gels in the presence of divalent cations (e.g., $\left.\mathrm{Ca}^{2+}\right)[3,13]$.

Several studies were conducted on the phenolic metabolites of several Myrtaceous plants [1416], which provide extracts rich in flavonoids, ellagitannins and gallotannins. Among them is Eugenia supra-auxillaris which is an evergreen tree, up to 25 feet long; leaves are elliptic- oblong, up to 5 inches long, with glossy upper side, pale beneath; flowers about 9 , in supra-axillary racemes. Literature survey on E. supra-auxillaris leaves showed potent hepato-protective activity and twelve phenolic metabolites were isolated and identified. They include the flavonoid glycosides; myricetin 3 -O- $\beta$-xylopyranosyl $(1 \rightarrow 2)$ - $\alpha$-rhamnopyranoside, myricetin 3-O- $\alpha$ - rhamnopyranoside and quercetin-3-O- $\quad \alpha$-rhamnopyranoside, the flavonoid aglycones; pinocembrin, myricetin and quercetin, together with phenolics; gallic acid, ellagic acid, 5-O-monogalloylquinic acid and nilocitin [17]. While the wood extract of this species proved potent antioxidant activity by the DPPH assay and ten phenolic compounds were characterized. The identified phenolics were gallic acid, 3,4-di-O-galloyl quinic acid , 3,4,5-tri-O-galloyl quinic acid, myricetin-3-O- $\beta$ xylopyranosyl $\quad(1 ", \rightarrow 2$ ")- $\alpha$-rhamnopyranoside, que r c e t i n - 3 - $O-\beta$ - x y l o p y r a n o s y 1 $(1$ "' $\rightarrow 2$ ")- $\alpha$-rhamnopyranoside, quercetin-3-O$\beta$-glucopyranoside (isoquercetin), myricetin-3- $O$ a-rhamnopyranoside, 3-O-monomethoxy ellagic acid-4'-O- $\alpha$-L-rhamnopyranoside, ellagic acid, 3-O-monomethoxyellagic acid, myricetin and quercetin [18].

Thus, the aim of this work was to initially inspect the total phenolic content and the antimicrobial activity of Eugenia supra-auxillaris

Egypt.J.Chem. Vol. 61, No.1 (2018) leaves against food borne bacteria and fungi. Afterward, studying the impact of encapsulating the bioactive fraction on their phenolic content and antimicrobial activity for their potential use as natural preservative in food industry.

\section{Materials and Methods}

\section{Plant material}

The leaves of Eugenia supra-auxillaris (family Myrtaceae) were collected from El-Zohreya Botanical garden, Horticulture Institute, Cairo, in November 2016. A flowering voucher specimen (M111) was deposited in the herbarium of the National Research Center (NRC), the identity of which was verified by Dr. Mona Marzouk, Associate Professor of Taxonomy at NRC.

\section{Extraction and fractionation}

The air dried Eugenia supra-auxillaris leaves $(2.7 \mathrm{~kg})$ were exhaustively percolated with $95 \%$ ethanol. The solvent was evaporated under reduced pressure using rotary vacuum evaporator leaving $60 \mathrm{~g}$ residue. Part of the alcoholic extract $48 \mathrm{~g}$ was dissolved in $400 \mathrm{ml}$ of distilled water/ alcohol mixture (9:1) and successively extracted with dichloromethane ( 3 X 400), ethyl acetate (3 X 500) and $n$-butanol (3 X 400). Each extract was separately evaporated to dryness using rotary vacuum evaporator under reduced pressure at a temperature. The resulted extracts were (9.8 g, $7.7 \mathrm{~g}$ and $6 \mathrm{~g}$ respectively). They were kept in refrigerator for chemical and biological investigation.

Folin-Ciocalteau assay for the estimation of total phenolics content

The phenolic content of the total extract, the ethyl acetate and $n$-butanol fraction were estimated by Folin-Ciocalteau reagent and expressed as gallic acid equivalents in $\mu \mathrm{g} / \mathrm{mg}$ of crude extract. The Folin-Ciocalteau assay relies on the transfer of electrons in alkaline medium from phenolic / antioxidant compounds to phosphomolybdic and phosphotungstic acid complexes, which can be determined by measuring the absorbance at $765 \mathrm{~nm}$ [19].

Instruments and materials for phytochemical investigation

${ }^{1} \mathrm{H}-\mathrm{NMR}$ spectra were measured by Bruker - 400 NMR spectrometer at $400 \mathrm{MHz} .{ }^{1} \mathrm{H}$ chemical shifts were measured relative to TMS and ${ }^{13} \mathrm{C}-\mathrm{NMR}$ chemical shifts to DMSO- $\mathrm{d}_{6}$ and converted to TMS scale by adding 39.5. Chromatographic analysis was carried out on Whatman No.1 paper using solvent systems: (1) 
$\mathrm{H}_{2} \mathrm{O}$; (2) 6\% HOAc; (3) BAW; (n-BuOH -HOAc - $\mathrm{H} 2 \mathrm{O}, 4: 1: 5$, upper layer).

\section{Isolation and structure elucidation}

The ethyl acetate fraction was investigated for its phenolic content. Three major phenolic metabolites were found among other minor components. The fraction was dissolved in water and applied to a polyamide 6s (Sigma- Aldrich, Sweden) column and eluted with $\mathrm{H}_{2} \mathrm{O}$ followed by $\mathrm{H}_{2} \mathrm{O}-\mathrm{MeOH}$ mixtures of decreasing polarities. The collected sub-fractions were investigated by two dimensional paper chromatography using BAW (n-buanol: acetic acid: water, 4:1:5) as the first solvent and $6 \%$ acetic acid as the second solvent. Compound (1) was isolated from subfraction I by crystallization. Compounds (2) and (3) were isolated from fraction II and III by preparative paper chromatography using BAW as an eluent. The isolates were identified according to their UV spectral data, ${ }^{1} \mathrm{H}-\mathrm{NMR}$ and ${ }^{13} \mathrm{C}$-NMR assignments.

\section{Microorganisms tested}

The microbial strains which were tested: Bacillus cereus B-3711(G+), Bacillus subtilus $(\mathrm{G}+)$, Aspergillus flavus 3357 and Saccharomyces cerevisiae Y-2223 provided by the Northern Regional Research Laboratory Illinois, USA (NRRL). Listeria monocytogenes (G-) 598 was provided by the Department of Food Science, University of Massashusetts, Ambert MA, USA. Escherichia coli 0157:H7 (G-) and Staphylococcus aureus $\left(\mathrm{G}^{+}\right)$were isolated and serologically identified by dairy microbiological Lab., National Research Center. Yersinia enterocolitica (G-) were obtained from Hungarian National Collection of Medical Bacteria, OKI, Gyaliut 2-6, H-1966 Budapest, Hungary. Aspergillus niger, Pseudomonas aeruginosa $\left(\mathrm{G}^{+}\right)$, Pencillium requfortii $\mathrm{J} 5$ were obtained from Department of Microbiology, Swedish University of Agricultural Sciences. Candidia albicans was provided by the Institute of Applied Microbiology, University of Tokyo, Japan. Salmonella typhamirum was provided from Hungarian National Collection of Medical Bacteria, OKI, Gyaliut 2-6, H-1966 Budapest, Hungary.

\section{Determination of antimicrobial activity}

Assessment of the antimicrobial activity against the selected bacterial and fungal strains was done according to the method described by Alam, M.T., et al., 2009 [20] at concentration of $100 \mathrm{mg} / \mathrm{ml}$. The same method was applied for the microencapsulated ethyl acetate fraction at concentrations of 100,50 and $25 \mathrm{mg} / \mathrm{ml}$. Antibacterial activity was defined as the diameter $(\mathrm{mm})$ of the clear inhibitory zone formed around the discs.

\section{Encapsulation process}

The ethyl acetate fraction was dried under vacuum in an evaporator at $50^{\circ} \mathrm{C}$ to dryness. Then dissolved in bi-distilled $\mathrm{H}_{2} \mathrm{O}$ at a concentration of $100 \mathrm{mg} / \mathrm{ml}, 50 \mathrm{mg} / \mathrm{ml}$ and $25 \mathrm{mg} / \mathrm{ml}$ then mixed with sodium alginate $2 \%$ solution (low viscosity, LOBA CHEME, India) under magnetic stirring. The microcapsules were prepared by the method described by El-Sayed et al., [21].

Measurement of particle size and zeta potential

The size and zeta potential of the formed microcapsules were determined using Zetasizer var. 704 instrument (Malvern Instruments, Malvern, UK). Samples were diluted with ultrapure MQ water before measuring light scattering of a laser beam $(633 \mathrm{~nm})$ at an angle of 173 at $25^{\circ} \mathrm{C}$ over time intervals. The changes in laser beam scattering versus time were used to determine the particle size distribution [22]. Zeta potential was measured in the same sample by electrophorsis and results were expressed as $\mathrm{mV}$.

Surface Phenolic Content (SPC) of the encapsulate and encapsulating efficiency

For the determination of surface phenolic compounds, $100 \mathrm{mg}$ of microcapsules were treated with $10 \mathrm{ml}$ of a mix of ethanol and methanol (1:1). The dispersion was agitated in a Vortex at room temperature for $1 \mathrm{~min}$ and then filtered (0.45 $\mathrm{lm}$ Millipore filter). The amount of phenolic compounds was quantified by the Folin-Ciocalteau assay given by Slinkard and Singleton [23].

The encapsulating efficiency was determined by using the given equation [24]

Encapsulating efficiency $(\%)=\frac{T P C-S P C}{T P C} \times 100$ Where, TPC is the total phenolic content before encapsulation; SPC is the surface phenolic content found on the microcapsules.

\section{Results and Discussion}

\section{Total phenolic content}

The total phenolic content in Eugenia supraauxillaris aqueous methanolic extract was established to be $21.625 \mu \mathrm{g}$ of GAEs/ mg of extract. While that of the ethyl acetate fraction was $33.36 \mu \mathrm{g}$ of GAEs/ mg and the $n$-butanol fraction had the lowest content of $5.99 \mu \mathrm{g}$ of GAEs/ mg. 


\section{Antimicrobial activity}

The aqueous methanolic extract of Eugenia supra-auxillaris leaves was screened for its antimicrobial activity against a number of foodborne pathogens including eight bacterial and five fungal strains at a concentration of $100 \mathrm{mg} /$ ml. (Table 1). The extract showed antibacterial activity against four bacterial strains and only one of the fungal strains tested.

TABLE 1. Antimicrobial activity of the aqueous methanolic leaves extract of Eugenia supra-auxillaris.

\begin{tabular}{ll}
\hline Bacterial strains tested & Diameter of inhibition zone $(\mathbf{m m})$ \\
\hline Bacillus cereus $\left(G^{+}\right)$ & 5 \\
Bacillus subtilus $\left(G^{+}\right)$ & 4 \\
Staphylococcus aureus $\left(G^{+}\right)$ & 6 \\
Pseudomonas aeruginosa $\left(G^{+}\right)$ & 4 \\
Listeria monoytogenes $\left(G^{-}\right)$ & n.d. \\
Escherichia coli $(G-)$ & n.d. \\
Salmonella typhamirum $(G-)$ & n.d. \\
Yersinia enterocolitica $(G-)$ & n.d. \\
Fungal strains tested & \\
Aspergillus niger & 4 \\
Aspergillus flavus & n.d. \\
Pencillium requfortii & n.d. \\
Saccharomyces cerevisiae & n.d. \\
\hline
\end{tabular}

This was followed by investigation of the ethyl acetate and $n$-butanol fractions against the affected strains. The ethyl acetate fraction possessed the highest antibacterial activity presented by larger diameter of the inhibition zone. (Table 2).

TABLE 2. Antimicrobial activity of the ethyl acetate and $\boldsymbol{n}$-butanol fraction.

\begin{tabular}{|c|c|c|}
\hline Microrganisms tested & $\begin{array}{l}\text { ethyl acetate fraction } \\
(100 \mathrm{mg} / \mathrm{ml})\end{array}$ & $\begin{array}{l}n \text {-butanol fraction } \\
(100 \mathrm{mg} / \mathrm{ml})\end{array}$ \\
\hline Bacillus cereus $\left(G^{+}\right)$ & 20 & 9 \\
\hline Bacillus subtilus $\left(G^{+}\right)$ & 25 & 10 \\
\hline Staphylococcus aureus $\left(G^{+}\right)$ & 12 & 17 \\
\hline Pseudomonas aeruginosa $(G+)$ & 14 & 11 \\
\hline Aspergillus niger & 5 & 4 \\
\hline
\end{tabular}

Isolation and structure elucidation.

According to the above findings, the ethyl acetate fraction was studied for its phenolic metabolites. Three phenolics were isolated and identified on the basis of their chromatographic behavior, UV spectral, ${ }^{1} \mathrm{H}$ and ${ }^{13} \mathrm{C}$ - NMR data which were in accordance with those previously reported, gallic acid, 5-O-monogalloylquinic acid and nilocitin [17].

Microencapsulation of the ethyl acetate fraction of Eugenia supra-auxillaris leaves within sodium alginate beads

Particle size and zeta potential of the formed microcapsules

The particle size and zeta potential of sodium Egypt.J.Chem. Vol. 61, No.1 (2018) alginate microcapsules of the ethyl acetate fraction are listed in Table 3.

The particle size of the ethyl acetate fraction was $3086 \mathrm{~nm}$. The high concentration loaded may be the reason of the large particle size obtained. The zeta potential of the ethyl acetate microcapsules was $-41.5 \mathrm{mV}$. The negative surface charge of sodium alginate micro-particles may be accredited to the presence of ionized carboxyl groups of alginate segments on the micro-particles surface. High absolute value of the zeta potential proposes high surface charge of the microparticles, suggesting strong repellent interactions among the micro-particles in dispersion [25]. 
TABLE 3. The particle size and zeta potential of sodium alginate microcapsules of the total extract and the ethyl acetate fraction.

\begin{tabular}{lccc}
\hline Treatments & $\begin{array}{c}\text { Size (nm) } \\
\text { By number }\end{array}$ & $\begin{array}{c}\text { Size (nm) } \\
\text { By intensity }\end{array}$ & Z-average (mV) \\
\hline Total extract capsules & 1246 & 1269 & -43.9 \\
$\begin{array}{l}\text { Ethyl acetate fraction } \\
\text { microcapsules }\end{array}$ & 3086 & 3159 & -41.5 \\
\hline
\end{tabular}

The surface phenolic content and the encapsulation efficiency

Determination of surface phenolic content of capsules was needed in order to calculate the encapsulation efficiency. The less the quantity of phenolics on the surface of the capsule, the more efficient the encapsulation process is. The surface phenolic content was found to $5.9 \mu \mathrm{g} / \mathrm{ml}$ for the ethyl acetate fraction microcapsules.
Thus, the encapsulation efficiency was calculated as $82.3 \%$ for the ethyl acetate fraction.

Antimicrobial activity of the encapsulated ethyl acetate fraction

The antimicrobial activity of the encapsulated ethyl acetate fraction was inspected at concentrations of $100 \mathrm{mg} / \mathrm{ml}, 50 \mathrm{mg} / \mathrm{ml}$ and 25 $\mathrm{mg} / \mathrm{ml}$. The encapsulated fraction retained its antimicrobial activity even when decreasing the concentration as low as $25 \mathrm{mg} / \mathrm{ml}$. (Table 4)

TABLE 4. Antimicrobial activity of the micro-encapsulated ethyl acetate fraction

\begin{tabular}{lccc}
\hline & \multicolumn{3}{c}{ Diameter of inhibition zone } \\
\hline Microrganisms tested & $100 \mathrm{mg} / \mathrm{ml}$ & $50 \mathrm{mg} / \mathrm{ml}$ & $25 \mathrm{mg} / \mathrm{ml}$ \\
Bacillus cereus $\left(\mathrm{G}^{+}\right)$ & 25 & 25 & 14 \\
Bacillus subtilus $\left(\mathrm{G}^{+}\right)$ & 20 & 21 & 9 \\
Staphylococcus aureus $\left(\mathrm{G}^{+}\right)$ & 20 & 26 & 5 \\
Pseudomonas aeruginosa $\left(\mathrm{G}^{+}\right)$ & 18 & 16 & 4 \\
Aspergillus niger & 16 & 12 & 5
\end{tabular}

\section{Conclusion}

Polyphenols are a remarkable group of active metabolites synthesized by plants, and show a unique combination of chemical, biological and physiological activities. However, their stability and/or solubility, often combined with a poor bioavailability have restrained their effective use in cosmetics, nutrition and health. In this study, the results of implementing micro-encapsulation to Eugenia supra-auxillaris extract and its ethyl acetate fraction confirmed that encapsulation could be an interesting practice of protection which preserves their antimicrobial activity. The encapsulation efficiency of sodium alginate was calculated as $82 \%$.

As a conclusion, microcapsules of the ethyl acetate fraction coated with sodium alginate $2 \%$ can be suggested to be merged as a food preservative since they had antimicrobial activity against the food-borne pathogens tested. Nevertheless, further research on storage stability, thermal stability and bioavailability of capsules incorporated in food will be followed before using microcapsules as food additives or nutraceuticals.

\section{Conflict of Interest}

The authors declare no conflict in interest.

\section{References}

1. Tajkarimi, M., Ibrahim, S. and Cliver D., Antimicrobial herb and spice compounds in food. Food Control 21 (9), 1199-1218 (2010).

2. Fang, Z. and Bhandari, B., Encapsulation of polyphenols - a review. Trends in Food Science \& Technology 21 (10), 510-523 (2010).

Egypt.J.Chem. Vol. 61, No.1 (2018) 
3. Desai, K.G.H. and Park, H.J., Recent development in microencapsulation of foods ingredients. Drying Technology; 23, 1361-1394 (2005).

4. Vandamme, T.F., Poncelet, D. and SubraPaternault, P. Microencapsulation: des sciences aux technologies, . Lavoisier Tec \& Doc: Paris, France (2007).

5. Arshady, R., Microspheres Microcapsules \& Liposomes: Preparation \& Chemical Applications. Citus Books: London, UK (1999).

6. Benita, S., Microencapsulation: Methods and Industrial Applications Taylor \&Francis: BocaRaton, FL, USA (2006).

7. Shanthi, C.N., Gupta, R. and Mahato, A.K.. Traditional and emerging applications of microspheres: A review. Int. J. PharmTech Res.; 2, 675-681 (2010).

8. Deladino, L., Anbinder, P.S., Navarro, A.S. and Martino, M.N., Encapsulation of natural antioxidants extracted from Ilex paraguariensis. Carbohydrate Polymers; 71, 126-134 (2008).

9. Belščak-Cvitanović, A., Stojanović, R., Manojlović, V., Komes; D., Cindrić, I.J., Nedović, V., et al. Encapsulation of polyphenolic antioxidants from medicinal plant extracts in alginate-chitosan system enhanced with ascorbic acid by electrostatic extrusion. Food Research International; 44, 1094-1101 (2011).

10. Stojanovic, R., Belscak-Cvitanovic, A., Manojlovic, V., Komes, D., Nedovic, V. and Bugarski, B., Encapsulation of thyme (Thymus serpyllum $\mathrm{L}$.) aqueous extract in calcium alginate beads. Journal of the Science of Food and Agriculture; 92, 685-696 (2012).

11. Deladino, L., Navarro, A.S. and Martino, M.N., Carrier systems for yerba mate extract (Ilex paraguariensis) to enrich instant soups: Release mechanisms under different $\mathrm{pH}$ conditions. Food Science and Technology; 53, 163-169 (2013).

12. Draget, K.I. and Taylor, C., Chemical, physical and biological properties of alginates and their biomedical implications. Food Hydrocolloids; 25(2), 251-256 (2011).

13. Fang, Y., Al-Assaf, S., Phillips, G.O., Nishinari, K., Funami, K. and Williams; P.A., Binding behavior of calcium to polyuronates: comparison of pectin with alginate. Carbohydrate Polymers; 72, 334-341 (2008).

Egypt.J.Chem. Vol. 61, No.1 (2018)
14. Hussein, S.A.M., Hashim, A.N.M., Seliem, M.A., Lindequist, U. and Nawwar, M.A., Polyoxygenated flavonoids from Eugenia edulis. Phytochemistry; 64, 883-889 (2003).

15. Hussein, S.A., Hegazi, N.M., Hashim, A.N. and Ayoub, N.A., Cytotoxic activities and potential antioxidant of Feijoa sellowiana leaf extract and its phenolic metabolites. Bull. Fac. Pharm. Cairo Univ.; 46 (2), 201-212 (2008).

16. Ayoub, N.A., Hussein, S.A., Hashim, A.N., Hegazi, N.M., Linscheid, M., Harms, M., et al. Bone mineralization enhancing activity of a methoxyellagic acid glucoside from a Feijoa sellowiana leaf extract. Pharmazie; 64, 137-141 (2009).

17. Barakat; H.H., El-Raey; M.A., Nada; S.A., Zeid; I.F. and Nawwar; M.A.M., Constitutive phenolics and hepatoprotective activity of Eugenia supraaxillaris leaves. Egyptian Journal of Chemistry; 54, 313 (2011).

18. El Raey; M., Proksch; P., Nawwar; M. and Barakat; H., New sulphated rhamnoside of ellagic acid monomethylether from Eugenia supra-axillaris of potent antioxidant activity. Planta Med; 80 - LP30 (2014).

19. Ainsworth; E.A. and Gillespie; K.M., Estimation of total phenolic content and other oxidation substrates in plant tissues using Folin-Ciocalteu reagent. Nature Protocols; 2 (4), 875-877 (2007).

20. Alam; M.T., Karim; M.M. and Khan; S.N., Antibacterial Activity of Different Organic Extracts of Achyranthes Aspera and Cassia Alata. J.Sci.RES; 1 (2), 393-398 (2009).

21. El-Sayed; M.M., Hassan; Z.M.R., Foda; M.I., Awad; R.A. and Salama; H.H., Chitosan -whey protein complex (cs-wp) as delivery systems to improve bioavailability of iron. International Journal of Applied and Pure Science and Agriculture; 1 (11), 34-46 (2015).

22. Salama; H.H., El-Sayed; M.M. and Abd ElSalam., Preparation of $\beta$-carotene Enriched Nanoemulsion by Spontaneous Emulsification Using Oleic Acid as Nano Carrier. Research Journal of Pharmaceutical, Biological and Chemical Sciences, 7 (4), 585-593 (2016).

23. Slinkard; S. and Singleton; V.L., Total phenol analysis: automation and comparison with manual methods. American Journal of Enology and Viticulture 28, 49-55 (1977). 
24. Cilek; B., Luca; A., Hasirici; V., Sahin; S. and Sumnu; G., Microencapsulation of phenolic compounds extracted from sour chery pomace: effect of formulation, ultrasonication time and core to coating ratio. European Food Research and Technology, 235 (4), 587-596 (2012).
25. Saénz; C., Tapia; S., Chávez; J. and Robert; P., Microencapsulation by spray drying of bioactive compounds from cactus pear (Opuntia ficusindica). Food Chemistry; 114, 616-622 (2009).

(Received 28/11/2017; Accepted 26/12/2017)

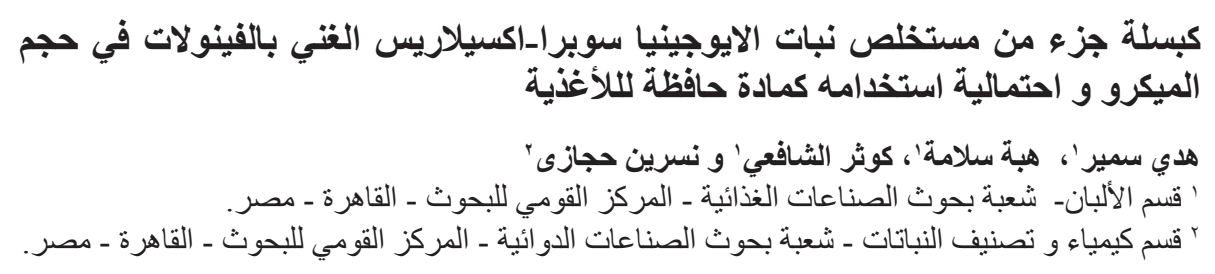

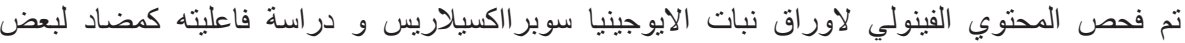

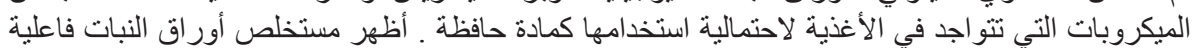

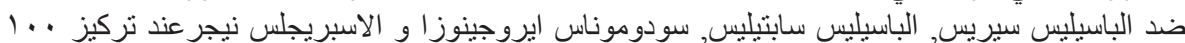

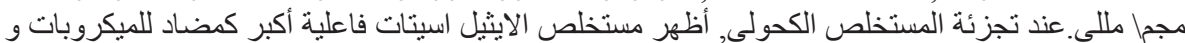

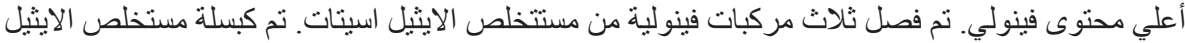

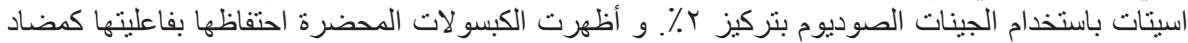

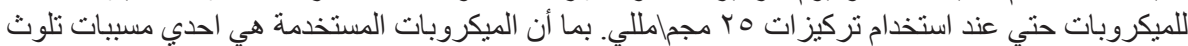

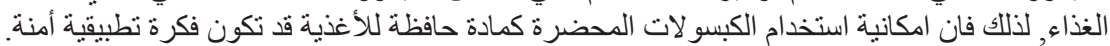

